\title{
Prevalence and aetiology of hypothyroidism in the young
}

Ian Hunter, Stephen A Greene, Thomas M MacDonald, Andrew D Morris

\begin{abstract}
Aims-To define the prevalence of hypothyroid disease in children and young people, and describe its aetiology.

Methods-We identified all patients on the Medicines Monitoring Unit (MEMO) database in the Tayside region of Scotland who had received two or more prescriptions for thyroxine during the study period (January 1993 to December 1995). Using this as a surrogate marker of hypothyroidism, we calculated the prevalence of hypothyroidism in those aged less than 22 years. Main outcome measures were prevalence of thyroxine prescription, estimated prevalence of hypothyroidism, and aetiology of the hypothyroidism (determined from case records, and biochemistry and immunology databases).

Results-Of 103500 residents aged less than 22 years, 140 were identified as receiving thyroxine on prescription, giving a population prevalence of $0.135 \%$. The ratio of male to female was $1: 2.8$. Acquired hypothyroidism was the commonest aetiology found in $73 \%, 66 \%$ of which had an autoimmune basis. The prevalence of congenital hypothyroidism was $\mathbf{0 . 0 2 7 \%}$. Seven had received treatment for malignancy (two primary thyroid). Fifteen per cent of patients had no record of secondary care follow up in Tayside.

Conclusions-The overall prevalence of hypothyroidism in young people less than 22 years of age is $0.135 \%$, and in the group aged $11-18$ years it is $0.113 \%$; these values are at least twice those of previous estimates. This suggests an increase in autoimmune thyroid disease, similar to the rising prevalence of type 1 diabetes, possibly indicating a rising incidence of autoimmunity in young people.

(Arch Dis Child 2000;83:207-210)
\end{abstract}

Keywords: hypothyroidism; prevalence; young people

Hospital and Medical

School, Dundee

DD1 9SY, UK

I Hunter

S A Greene

Medicines Monitoring Unit, Ninewells Hospital and Medical School

T M MacDonald

A D Morris

Correspondence to:

Dr Hunter

email:

i.hunter@dundee.ac.uk

Accepted 22 May 2000

Prevalence rates for congenital hypothyroidism are well described, whereas acquired hypothyroidism in the young has been less well documented, particularly in recent years.

Primary congenital hypothyroidism has a comparable incidence worldwide (1:30001:4000 live births, ${ }^{1}$ with recent quoted figures in Holland of 1:3400 for primary congenital hypothyroidism and 1:25000 for secondary hypothyroidism. ${ }^{2}$ In Scotland the incidence was estimated at 1:4350 births over the years 1980-1993. ${ }^{3}$ Of these approximately $2 \%$ (1:180 000 of all live births) have transient hypothyroidism secondary to maternal antibodies, ${ }^{4}$ and up to $5 \%$ may have transient hypothyroidism secondary to prematurity. ${ }^{5}$

Previous estimates of the prevalence of acquired hypothyroidism in children and adolescents, based on selected populations with few population studies, have ranged between $0.04 \%$ and $0.06 \% .^{6-8}$ Using Medline $1966-$ 1999 we were unable to find any study describing the overall prevalence of clinical hypothyroidism in the 0-22 year age range.

Because thyroxine should be given to young people only if they are clinically and biochemically hypothyroid, prescription of the drug can be used as a surrogate marker of hypothyroidism. Our study aimed to define the population prevalence of patients receiving thyroxine prescription in young people less than 22 years of age, and from this the prevalence of hypothyroidism in the young.

\section{Subjects and methods}

SUBJECTS

The study population comprised all residents of the Tayside region of Scotland, less than 22 years of age on 1 January 1994, who were alive and remained resident in the region throughout the study period.

METHODS

Every patient who is registered with a general practitioner in Scotland is allocated a unique identifying number called the community health number (CHI) consisting of 10 digits, the first six being the date of birth. Every resident of Tayside is registered and appears in the centrally held, continuously updated computerised record, the Community Health Master Patient Index. This file contains data on patients' address and postcode, general practitioner, death, and date of death. Thus, the data analyse the demographic breakdown of the Tayside population, deaths, and patient migration. The CHI number is also used as the patient identifier in all healthcare activities in Tayside, both in primary and secondary care.

All prescriptions within the region (including thyroxine) are registered on a database generated by the Medicines Monitoring Unit (MEMO). This unit, based at Dundee University, has been described in detail elsewhere. ${ }^{9}{ }^{10}$ Briefly, it has devised a method of capturing person specific dispensing for the whole of Tayside and, since January 1993, has recorded over 15 million prescription items specified by $\mathrm{CHI}$ number. From the MEMO database, we identified all prescriptions for thyroxine prescribed to all subjects less than 22 years of age between 1 January 1993 and 31 December 1994. 


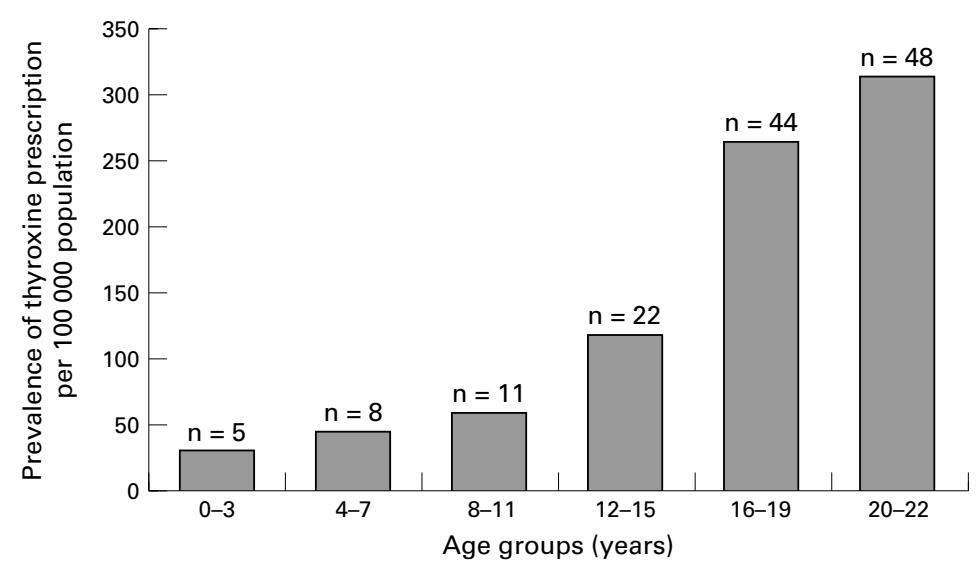

Figure 1 Prevalence of thyroxine prescription for specific age groups; $n=140$.

We inspected individual hospital case records (but not primary care case records), and clinical biochemistry and immunopathology computerised databases of the cohort to confirm the diagnosis and indication for thyroxine replacement. The following were also recorded: age at mid point of study (1 January 1994), age at diagnosis, sex, aetiology of clinical hypothyroidism, comorbidities, thyroid stimulating hormone (TSH) and serum thyroxine concentration at the time of diagnosis (reference ranges: TSH $0.4-4.0 \mathrm{mIU} / 1$, free thyroxine $10-23 \mathrm{pmol} / \mathrm{l}$; all tests performed in one laboratory in Tayside), autoantibody status (microsomal and thyroglobulin antibody tests, normal <1:40), and whether the subject was under primary care or hospital follow up. We regarded TSH greater than $4 \mathrm{mIU} / 1$ and free thyroxine less than $10 \mathrm{pmol} / 1$ as diagnostic of hypothyroidism. We excluded patients notified on the MEMO database as receiving only one thyroxine prescription during the study period. We obtained denominators for the calculation of the prevalence of thyroxine prescription from the community health master patient index. All patient ages were calculated at the mid point of the study period.

\section{Results}

Using the Tayside database, 103500 young people less than 22 years of age were identified as living in Tayside between January 1993 and December 1995. During the study period, 140 children and adolescents received more than one prescription for thyroxine, giving a presumed population prevalence of hypothyroidism of $0.135 \%$. There were 37 men and 103 women, a ratio of $1: 2.8$. Figure 1 shows the age distribution for thyroxine prescription.

The aetiology was known in $85 \%$ of patients, and determined through examination of the hospital case records, where available, and record linkage using the patients' CHI numbers to clinical biochemistry and immunopathology records. Case records and biochemistry were available for $79 \%$ and case records only for $6 \%$. Encashment of two or more prescriptions for thyroxine (presumed hypothyroid) was documented in the remaining $15 \%$, but we identified no secondary care case records for these patients; however, 15\% had
Table 1 Number, percentage, and disease aetiology of patients with acquired hypothyroidism

\begin{tabular}{ll}
\hline Aetiology of acquired hypothyroidism & Number (\%) \\
\hline Hashimoto's-hypothyroid presentation & $43(49)$ \\
Hashimoto's-thyrotoxic presentation & $7(8)$ \\
Graves' disease - thyroid stimulating & $8(9)$ \\
$\quad$ antibodies positive & $7(8)$ \\
Secondary to malignancy & $22(25)$ \\
Idiopathic hypothyroidism & $87(100)$ \\
Total & \\
\hline
\end{tabular}

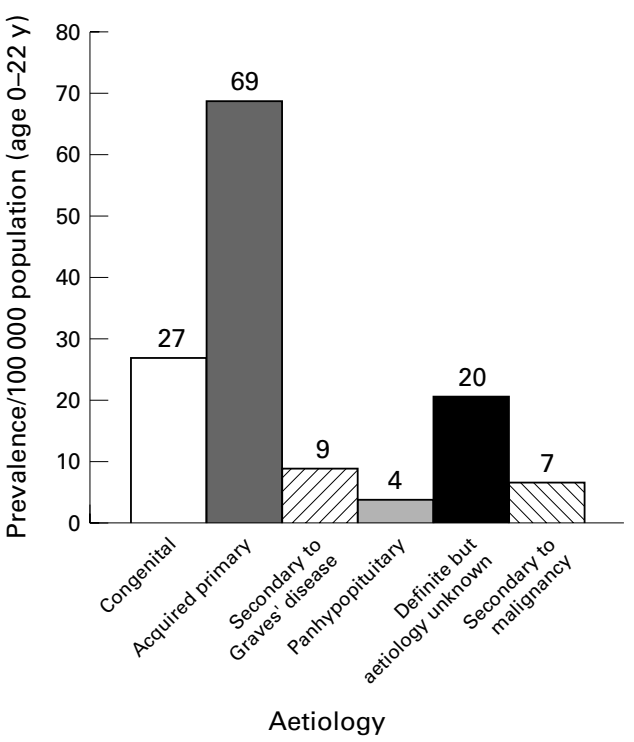

Figure 2 Prevalence of thyroxine prescription in other aetiologies.

biochemical evidence of hypothyroidism. The average age of this group was 16.9 years (range 7-22).

Acquired primary hypothyroidism was the commonest reason for thyroxine prescription in the cohort with a prevalence of $0.067 \%$; fig 2 shows the remaining aetiologies and population prevalence. Of the cohort, $87(73 \%)$ had an acquired cause of hypothyroidism; table 1 shows details of this group. The prevalence in young people aged 11-18 years for acquired hypothyroidism - that is, those patients who received thyroxine prescription, excluding congenital hypothyroidism and congenital panhypopituitary causes, was $0.113 \%$.

Of the children and young people with malignancy $(n=7)$, two had primary thyroid carcinoma diagnosed at 15 years, and one had a thyroidectomy for a cold nodule; the remainder had developed hypothyroidism secondary to treatment for other malignancies including Hodgkin's disease and leukaemia.

Of the 140 patients, $7.1 \%$ had a comorbidity, $3.5 \%$ had type 1 diabetes mellitus, $1.5 \%$ Down's syndrome, and $2.1 \%$ juvenile idiopathic arthritis.

\section{Discussion}

Our population based study has defined the prevalence of clinical hypothyroidism in young people less than 22 years of age in a geographically defined area. Previous studies have either been based on selected populations, ${ }^{611-14}$ or have investigated a population of later school age children (11-18 years of age). ${ }^{78}$ Thyroxine 
is only given to young people if they are clinically and biochemically hypothyroid, with the possible exception of reduction of a euthyroid goitre compressing surrounding structures. Using thyroxine prescription as a surrogate marker, therefore, will give absolute specificity for the prevalence of clinical hypothyroidism in this age group. Given that the database used to generate the patients receiving thyroxine, the case records, and clinical laboratory data set all use the CHI number, further validation of the database was possible.

Our study has defined a population prevalence for hypothyroidism of 135:100 000 for young people less than 22 years of age, two to three times higher than the previously published prevalence rate. ${ }^{6}$ In children of later school age (11-18 years of age) we have defined a prevalence of acquired hypothyroidism of $0.113 \%$. A large prospective study performed in Utah and Arizona, USA in 19651968, with patients followed up as adults in 1985 to 1987 , showed a population prevalence of $0.06 \%$ for hypothyroidism. ${ }^{7}$ A study of 5462 Croatian schoolchildren of the same age group, screened for thyromegaly and reported in 1994 , contained five children $(0.09 \%)$ with either an abnormal TSH or thyroxine value (or both). Three of these children $(0.055 \%)$ were either overtly hypothyroid or had biochemical hypothyroidism. The remaining two children had increased TSH but normal thyroxine concentrations. None were on treatment with thyroxine before the study. ${ }^{8}$ The methodology of both these population studies was different to our own, in that they both identified thyroid abnormality by first screening the children for physical abnormality of the thyroid, whereas we identified hypothyroidism using treatment with thyroxine and would therefore expect to "miss" subclinical disease, and hence underestimate the prevalence of thyroid disease.

Our increased prevalence rate may represent variation in different parts of the world, but we note that the Utah/Arizona study showed a prevalence of hypothyroidism in adults of $1.6 \%{ }^{7}$ similar to the 1977 Whickham, UK survey of $1-1.5 \% .^{15}$

The majority of our cohort (66\%) who had acquired hypothyroidism had an autoimmune basis for their disease, so our findings may reflect an increase in the prevalence of autoimmune thyroid disease. This appears to mirror the rising incidence of type 1 diabetes mellitus, seen in Scotland. ${ }^{16}$ Similarly, the prevalence of other diseases mediated through the immune system such as childhood allergies ${ }^{17}$ and asthma ${ }^{18-20}$ is currently rising in the young. It has been suggested that this may be caused by a decrease in exposure to infection in early life. ${ }^{212}$ This hypothesis is supported by the demonstration that children from small families had an increased prevalence of atopy if they started day nursery at an older age. ${ }^{23}$ The anthroposophic lifestyle, including incomplete immunisation and less use of antibiotics, has recently been claimed to lead to a lower prevalence of allergic disease and atopy. ${ }^{24}$ Thus lifestyle and secular changes over recent years may be responsible for an increase in disease mediated through the immune system.

All causes of clinical hypothyroidism are represented in this cohort of children and young people, including two cases of thyroid carcinoma, which were both diagnosed when the patients were 15 years old. The prevalence of congenital primary hypothyroidism of $0.27 \%(27: 100000)$ was consistent with the incidence in Scotland over the last 20 years. ${ }^{5}$

No secondary care follow up was identified in $15 \%$ of the cases with an average age of 16.9 years. We presume that the majority of this cohort are either being followed exclusively in primary care or receiving specialist follow up outside Tayside.

Our study has shown that the cohort suffered from additional comorbitities. In 3.5\% the hypothyroidism coexisted with type 1 diabetes mellitus, consistent with the known increased prevalence of other autoimmune conditions in this disorder. An additional 2\% suffered from the combination of juvenile idiopathic arthritis and hypothyroidism, which raises the question of whether it might be of value to screen routinely for thyroid autoantibodies in juvenile idiopathic arthritis to detect the disease before clinical decompensation. In the cohort, $1.5 \%$ had Down's syndrome, confirming the well known association of these two conditions, and further justifying screening for hypothyroidism in Down's syndrome.

In summary, our study has defined a prevalence of clinical hypothyroidism in Tayside, Scotland which strongly suggests a rising prevalence of autoimmune thyroid disease in children and young people; we recommend further population studies to investigate this important finding.

1 Gruters A. Screening for congenital hypothyroidism. Baillieres Clinical Paediatrics: Paediatric Endocrinology Baillieres

2 Verkerk PH, Derkson-Lubsen G, Vulsma T, Loeber JG, de Vijlder JJ, Verbrugge HP. Evaluation of a decade of neonatal screening for congenital hypothyroidism in the Netherlands. Nederlands Tijdschrift voor Geneeskunde 1993;137: 2199-205.

3 Ray M, Muir TM, Murray GD, Kennedy R, Girdwood RWA, Donaldson MDC. Audit of screening programme for congenital hypothyroidism in Scotland 1979-93. Arch Dis Child 1997;76:411-15.

4 Brown RS, Belisario RL, Botero D, et al. Incidence of transient congenital hypothyroidism due to maternal thyrotropin receptor blocking antibodies in over one million babies. f Clin Endocrinol Metab 1996;81:1147-51.

5 Rooman RP, Du Caju MV, De Beeck LO, Docx M, Van Reempts P, Van Acker KJ. Low thyroxinaemia occurs in the majority of very preterm newborns. Eur f Pediatr 1996;156: 337.

6 Lafranchi SH. Hypothyroidism. Pediatr Clin North Am 1979;26:33-51.

7 Rallison ML, Dobyns BM, Meikle AM, Bishop M, Lyon JL, Stevens WS. Natural history of thyroid abnormalities: prevalence, incidence, and regression of thyroid diseases in adolescents and young adults. Am F Med 1991;91:363-70.

8 Jaksic J, Dumic MJ, Filipovic B, Ille J, Cvijetic M, Gjuric G. Thyroid diseases in a school population with thyromegaly. Arch Dis Child 1994;70:103-6.

9 MacDonald TM, McDevitt DG. The Tayside medicines monitorung unit (MEMO). In: Strom BL, ed. Pharmacoepidemiology. Chichester: Wiley, 1994:245-55.

10 Evans JMM, MacDonald TM, McDevitt DG. The Tayside medicines monitoring unit (MEMO): a record linkage system for pharmacovigilance. Pharm Med 1995;9:177-84.

11 Fisher DA, Oddie TH, Johnson DE, Nelson JC. The diagnosis of Hashimoto's thyroiditis. F Clin Endocrinol Metab 1975;40:795-801.

12 Adams HD. Non toxic nodular goiter and carcinoma of the thyroid in children 15 years of age and younger. Surg Clin North Am 1967;47:601-5. 
13 Greenberg Ah, Czernichow P, Hung W, Shelley W, Winship T, Blizzard RM. Juvenile chronic lymphocytic thyroiditis clinical, laboratory and histological correlations. I Clin Endocrinol 1970;30:293-301

14 Maenpaa J. Juvenile goitrous autoimmune thyroiditis. Acta Paediatr Scand 1972;61:49-62.

15 Tunbridge WM, Evered DC, Hall R, et al. The spectrum of thyroid disease in a community: the Whickham survey. Clin Endocrinol 1977;7:481-93.

16 Rangasami JJ, Greenwood DC, McSporran B, Smail PJ, Patterson CC, Waugh NR. Rising incidence of type 1 diabetes in Scottish children, 1984-93. The Scottish Study Group for the Care of Young Diabetics. Arch Dis Child 1997;77:210-13.

17 Woolcock AJ, Peat JK, Trevilion LM. Changing prevalence of allergies worldwide. Prog Allergy Clin Immunol 1995;3:167-71.

18 Ninan TK, Russel G. Respiratory symptoms and atopy in Aberdeen schoolchildren: evidence from two surveys 25 years apart. BMF 1992;304:873-5.
19 Burr ML, Butland BK, King S, Vaughan Williams E. Changes in asthma prevalence; two surveys 15 years apart. Arch Dis Child 1989;64:1452-6.

20 Robertson CF, Heycock E, Bishop J, Nolan T, Olinsky A, Phelan PD. Prevalence of asthma in Melbourne schoolchildren: changes over 26 years. BMF 1991;302: 1116-18.

21 Cookson WOCK, Moffatt MF. Asthma: an epidemic in the absence of infection? Science 1997;275:41-2.

22 Martinez FD. Role of viral infections in the inception of asthma and allergies in childhood: could they be protective? Thorax 1994;49:1189-91.

23 Kramer U, Heinrich J, Wyst M, Wichmann H-E. Age of entry to day nursery and allergy in later childhood. Lancet 1999;353:450-4.

24 Alm JS, Swartz J, Lilja G, Scheynius A, Pershagen G. Atopy in children of families with an anthroposophic lifestyle. Lancet 1999;353:1485-8.

\section{Teething again}

One of the more frequently quoted aphorisms of the late Professor Ronald Illingworth stated that "teething produces nothing but teeth". Nevertheless, the belief that teething may produce symptoms such as mild fever, drooling, disturbed sleep, rash, or diarrhoea has been difficult to nail. Now a prospective study in Cleveland, Ohio (Michael L Macknin, and colleagues. Pediatrics 2000;105:747-52) has shown that symptoms do increase in the days before and after eruption of a tooth.

The parents of 125 well children agreed to make daily observations of their children between the ages of 4 months and 1 year, recording 18 different symptoms, twice daily temperature by ear thermometer, and tooth eruptions. They were told that the study was of normal development without emphasis on the effects of teething. There was a period of eight days around tooth eruption (four days before, the day of eruption, and three days after) when some symptoms increased in frequency. These symptoms were increased biting, drooling, gum rubbing, sucking, irritability, wakefulness, ear rubbing, facial rash, poor appetite for solids, and mild temperature elevation. Diarrhoea, vomiting, cough, sleep disturbance, and non-facial rash were not significantly increased.

Despite these findings it was not possible to define any symptom cluster which reliably predicted tooth eruption. No single symptom was more than $20 \%$ more frequent in teething than in non-teething periods. Similarly, there were 2067 child-days of temperature over $100^{\circ} \mathrm{F}$ but a tooth erupted on only 64 of those days.

Mild symptoms may be common before, during, and after tooth eruption but they are unreliable predictors of tooth eruption and should not be dismissed as teething symptoms without considering other possibilities.

ARCHIVIST 